\title{
Wirksam managen im Gesundheitssystem 2003
}

Fördern Sie Ihre Effektivität als Führungskraft! Denn komplexe anstehende Systemveränderungen im Gesundheitswesen verlangen neue Führungskompetenzen von Berufspersonen. Das interdisziplinäre Weiterbildungsprogramm «Wirksam managen im Gesundheitssystem» bietet Ihnen die Möglichkeit, Ihre Führungskompetenz zu entfalten und ein breites Führungsinstrumentarium in einer stimulierenden Atmosphäre zu entwickeln.

Wir fokussieren eine berufsübergreifende Lernkultur, die Ihnen erlaubt, neues Wissen mit Ihrer eigenen Berufssituation und den für Sie wichtigen Fragen und Aufgaben zu verbinden sowie in realen Projekten aus Erfahrenem und Erlebtem zu lernen.

\section{Themen und Lernziele}

\section{Element 1: Führen als Intervention}

Führungsverständnisse, -stile und -instrumente; Die Entwicklung des Gesundheitswesens als Kontext zur Führung; Systemisches Denken und Handeln.

Element 2: Sich selbst und andere führen Selbstmanagement; Menschen führen: Individualitäten, Prozesse, Dynamiken; Teams in Organisationen des Gesundheitswesens.

\section{Element 3: Projekte managen}

Projektmanagement; Gesundheitsökonomie; Durchführung eines realen Projektes.

\section{Element 4: Organisationen entwickeln}

Organisationsentwicklung und -dynamik; Strategisches Management; Führung und Komplexität; Auftrittskompetenz.

\section{Element 5: offener Raum \\ Selbstorganisation.}

\section{Element 6: Integration}

Die vielfältigen Facetten der Führung; Rückblick und Ausblick.

\section{Teilnehmende}

Als Teilnehmende sind Sie erfolgreiche Gesundheitsfachperson mit Führungsfunktionen. Vielleicht sind Sie in Ihrem Arbeitsumfeld zusätzlich mit grösseren Veränderungen konfrontiert oder Sie möchten Ihrer Karriere eine neue Richtung geben. Unser oberstes Ziel ist es, Ihre Führungskompetenzen zur vollen Entfaltung zu bringen.

\section{Daten und Leitung}

$\begin{array}{lll}\text { Element 1 } & \text { 14.-16. Mai 2003 } & \text { 3 Tage } \\ \text { Element 2 } & \text { 30. Juni-2. Juli 2003 } & \text { 3 Tage } \\ \text { Element 3 } & \text { 20.-23. August 2003 } & \text { 4 Tage } \\ \text { Element 4 } & \text { 1.-3. Oktober 2003 } & \text { 3 Tage } \\ \text { Element 5 } & \text { 29.-31. Oktober 2003 } & \text { 3 Tage } \\ \text { Element 6 } & \text { 27.-28. November 2003 } & \text { 2 Tage }\end{array}$

Verantwortliche Programmleiter

PD Dr. med. Peter Berchtold, Leiter College-M, Bern

Dr. Christoph Schmitz, Corporate Pragmatics, Zürich

Ort: College-M, Freiburgstrasse 41, 3010 Bern

Preis: Fr. 7950.- (darin enthalten sind sämtliche Programmaktivitäten und Unterlagen)

\section{Link}

Das Programm «Wirksam managen im Gesundheitssystem» kann mit dem «HADmedical Basisund Aufbaukurs» des Departements Anästhesie der Universitätskliniken Basel verknüpft werden.

\section{Informationen und Anmeldung}

Detaillierte Informationen finden Sie unter http://www.college-m.ch/bildung/FE2.htm

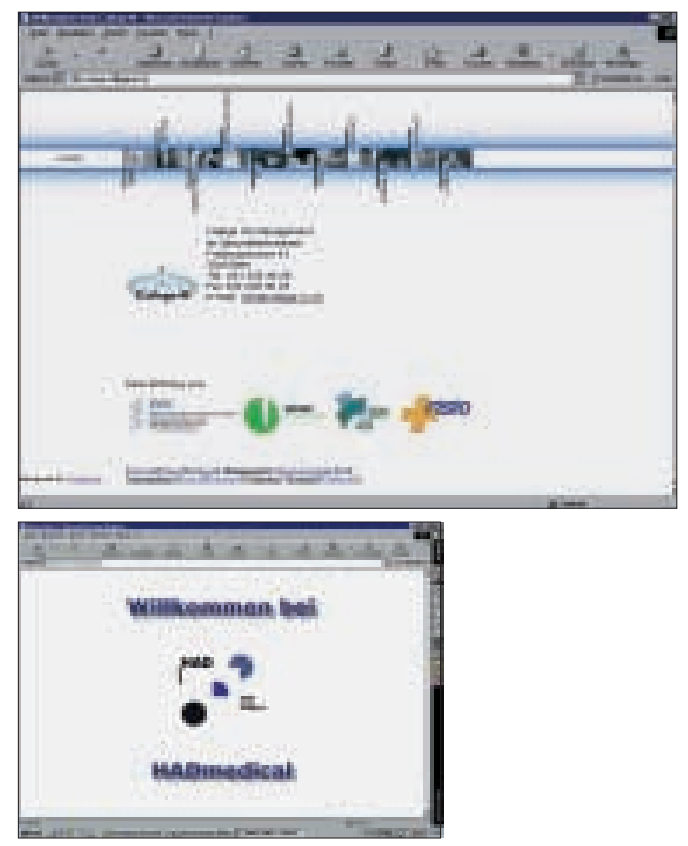

College-M, Freiburgstrasse 41, 3010 Bern Tel. 03163230 26, Fax 0316323025 E-Mail: info@college-m.ch 